\title{
Effects of overdenture attachment systems with different working principles on stress transmission: A three-dimensional finite element study
}

\author{
Nurullah Turker*, Ulviye Sebnem Buyukkaplan \\ Department of Prosthodontics, Faculty of Dentistry, Akdeniz University, Antalya, Turkey
}

\begin{abstract}
PURPOSE. The aim of the present study was to compare the stress distributions on the dental implants, abutments, and bone caused by different overdenture attachment types under functional chewing forces. MATERIALS AND METHODS. The 3D finite element models of the mandible, dental implants, attachment types, and prostheses were prepared. In accordance with a conventional dental implant supported overdenture design, the dental implants were positioned at the bone level in the canine teeth region bilaterally. A total of eight models using eight different attachment systems were used in this study. All the models were loaded to simulate chewing forces generated during the centric relationship $(450 \mathrm{~N})$, lateral movement $(400 \mathrm{~N})$, protrusive movement $(400 \mathrm{~N})$, and also in the presence of a food mass unilaterally $(200 \mathrm{~N})$. Stress outputs were obtained as the maximum principal stress and the equivalent von-Mises stress. RESULTS. In all attachment types, higher stress values were observed in the abutments, dental implants, and bone in the magnet attachments in different loading conditions. The highest stress values were observed among the magnet systems in the components of the Titanmagnetics model in all loading conditions (stresses were 15.4, 17.7, and 33.1 MPa on abutment, dental implant, and bone, respectively). The lowest stress value was observed in the models of Zest and O-Ring attachments. CONCLUSION. The results of the present study implied that attachment types permitting rotation and tolerating various angles created lower stresses on the bone, dental implants, and abutments. [J Adv
\end{abstract}

Prosthodont 2020;12:351-60]

KEYWORDS: Dental implants; Mandible; Finite element analysis; Occlusion

\section{INTRODUCTION}

The contribution of dental implant-retained overdentures to the quality of life in the elderly has been proven in the dental literature. ${ }^{1}$ It has also been proved in the studies that two dental implants are enough to support a mandibular

Corresponding author:

Nurullah Turker

Department of Prosthodontics, Faculty of Dentistry, Akdeniz University, 07058, Konyaaltı, Antalya, Turkey

Tel. +902422274400/5866: e-mail, nurullahturker@hotmail.com

Received April 30, 2020 / Last Revision July 19, 2020 / Accepted September

3,2020

(C) 2020 The Korean Academy of Prosthodontics

This is an Open Access article distributed under the terms of the Creative Commons Attribution Non-Commercial License (http://creativecommons. org/licenses/by-nc/4.0) which permits unrestricted non-commercial use, distribution, and reproduction in any medium, provided the original work is properly cited.

The study was supported by Akdeniz University Scientific Research Projects Support Unit (Grant Number: TSA-2019-4750). The authors have no conflicts of interest relevant to this article. overdenture. $^{2}$ Overdenture patients are generally of older ages $^{3}$ and consequently most elderly patients have some systemic diseases that comprise the management of the dental implant treatment. ${ }^{4}$ Advanced age and the systemic problems of overdenture patients necessitate that desirable dental implant management should have a minimal intervention for the surgical and prosthetic maintenance of the overdenture after the delivery of the final prosthesis. This means that the stresses should be minimally transferred to dental implants via the overdenture and its housings to ensure less implant maintenance interventions. Thus, the main goals of the selection among the different attachment types for overdentures are to provide insight into the biological effects of interfacial stress transfer and the most favorable delivery of forces to the dental implant.,

In contemporary dentistry, there are various attachment systems that allow the removable denture to attach to the dental implants. ${ }^{7}$ Attachment systems can be classified according to whether the implants are splinted or not. ${ }^{8}$ In case dental implants are splinted, the connection between 
the prosthesis and dental implant is provided with bar structures. If the dental implants are not splinted, each dental implant is individually attached to the prosthetic structure. This connection is provided with Locator, ERA, ball, O-ring and various magnet systems. These attachment types can also be classified according to working principles. The attachment types on which the plastic patrix sits on the abutment (Locator) do not allow the patrix to perform rotational and rolling movements on the abutment. Attachment types that have ball-headed abutment (ball, O-ring) allow the patrix to perform these movements to varying degrees. However, there are also new attachment types that are of the Locator type and allow for these movements (Zest Anchors LLC, Escondido, CA, USA). Magnet attachment systems work by the principle of magnetization between parts. The selection of attachment type is affected by the dental implant location, degree of retention, the morphology of the edentulous jaw, and the patient's motor dexterity.' The most preferred overdenture attachment type is the Locator and ball because of its ease of application, lesser technical requirements, and lower cost compared to the bar or magnet systems. There is still an effort to offer better attachment systems in dental implantology.

The prognosis of dental implants greatly depends on the stress and load distribution of occlusal loads transferred via the attachment systems to the dental implants; in the dental literature, there are numerous studies that have evaluated the stress and occlusal load distribution on the dental implants and supporting tissues transferred via the attachments. ${ }^{9,10}$ Daas et al. ${ }^{11}$ investigated the rigid and resilient attachment configurations, and they concluded that "resilient attachments allowed for an increase of the mastication load transiting through denture bearing surface". Due to various deficiencies in existing attachments and certain commercial concerns, new dental systems are being introduced to the dental market day by day. Today, there are many overdenture attachment systems in the dental field, which are advantageous in various aspects. The aim of the present study was to compare the stress values on the implant, abutment, and bone caused by different overdenture attachment types with 3D finite element analysis. The null hypothesis was that attachment types working with different principles do not cause different amounts of stress on bone tissue and dental implant parts.

\section{MATERIALS AND METHODS}

The mandible model was modeled as a single layer through the Autodesk Meshmixer (Autodesk Inc., San Rafael, CA, USA) software taking an anatomy book as a reference and in the light of the data on the dimensions of the mandible in the literature. ${ }^{12,13}$ This model did not have cortical and trabecular bone layers. The model obtained to create these structures was transferred to the Space Claim (ANSYS Inc., Canonsburg, PA, USA) software. At this stage, gingival tissue with a thickness of $1 \mathrm{~mm}$, cortical bone with a thickness of $2 \mathrm{~mm}$, and trabecular bone structure with thicknesses varying by area were modeled with "shell" and "subtract" procedures. To model the prosthetic structure, a mandibular and maxillary dental prosthesis containing twenty-eight teeth was prepared by a dental technician to have the basic characteristics of a bilateral balanced occlusion. Only the mandibular prosthesis was scanned with a three-dimensional scanning device (D250; 3Shape, Copenhagen, Denmark) and a 3D image of the prosthesis was obtained in an STL format. The obtained image was transferred to Space Claim software and positioned on the mandible model, which had gingival, cortical bone, and trabecular bone layers. This model consisting of bone tissue and a prosthetic structure was transferred to the Autodesk Meshmixer software. Formal compatibility was ensured between the mandible and the intaglio surface of the prosthesis. The prosthetic structure was finalized at this stage.

The design of the dental implant and attachment parts was performed in the Design Modeler module of the Ansys software (ANSYS Inc., Canonsburg, PA, USA). A rootshaped dental implant, which was available in the market, had a length of $10 \mathrm{~mm}$ and was $4 \mathrm{~mm}$ in diameter; this was used as a reference in the design of the dental implants (OsseoSpeedtx 4.0 S, Astra Tech, Lausanne, Switzerland). The dental implant was modeled considering the three times bigger implant demo and the size data in the introductory catalog. The neck part of this dental implant was rearranged in a way to ensure the adaptation of eight different attachment types to be tested in the study (Fig. 1). In the final form of the design, the dental implant structure was of the internal non-hex type. Ball (BioHorizons IPH Inc., Birmingham, AL, USA), Locator (BioHorizons IPH Inc., Birmingham, AL, USA), ERA (Sterngold Dental LLC, Attleboro, MA, USA), O-Ring (BioHorizons IPH Inc., Birmingham, AL, USA), Zest (Zest Anchors LLC, Escondido, CA, USA) Dentium Magnet (Dentium Inc., Seoul, Korea), Dyna Magnet (Dyna Dental Engineering, Golden, CO, USA), and Titanmagnetics (Steco-system-technik, GmbH \& Co., Hamburg, Germany) attachments were designed. The product catalogs of the companies were used in the design of all the parts belonging to the attachments tested in the study. However, the details that are not included in the catalogs and that are required for the design were obtained by contacting the manufacturer. The sections of the designed attachments obtained in the Space Claim software are shown in Figure 1. Since two as left and right side of bone will be used for each model, by using the copying method, 16 dental implants were created and the number of each attachment system parts was doubled by copy method.

Dental implant and bone structures were transferred to the ANSYS Design Modeler module in order to combine all the designs. The dental implants were positioned at the bone level in the canine teeth area at a distance of $17 \mathrm{~mm}$ from the midline. Bone, dental implant, and prosthetic structure compatibility were provided with the subtract procedure. The obtained model was the standard for all of the eight different models to be created for the attachments. Eight separate copies were obtained from this model to be 
used separately for each attachment. The pre-designed eight different attachments were assembled for these models, and the adaptation to the structure was enabled through the "subtract" procedure (Fig. 1, Fig. 2).

Material properties were defined for all the models with reference to the previous studies (Table 1). ${ }^{14-18}$ All the parts were accepted as homogeneous and isotropic. The contact between the bone and the dental implant was defined as "bonded" to represent 100\% osseointegration. ${ }^{19}$ The coefficient of friction was defined as 0.4 on the areas where the sliding would occur, defining the contact relationship between the attachment parts. ${ }^{20}$ These areas were between attachment - plastic patrix parts of Ball, ERA, Locator, Zest, and O-ring attachment types. $3 \mathrm{~N}$ of magnetic force was applied to each magnet attachment to represent a $300 \mathrm{~g}$ attachment, taking into account the properties of the attachment specified in the product catalogs. The coefficient of friction between the intaglio surface of the prosthesis and mucosa was set as $0.334 .^{21}$ The contact between all the other parts was defined as "bonded".

In the present study, detailed designs were made for a more realistic simulation (such as dental implant and abutment grooves). In order not to turn the difficulties caused by this detailing into a disadvantage, manual mesh refinement was performed on the parts and surfaces where the stress outputs were taken. With this method, through the selective distribution of elements and dimensions, the refinement was carried out in the special regions of interest (abutments, dental implants, and bone tissue around the dental implant) in the analysis. Stress outputs were taken and models were examined. Repeated mesh refinement was performed in regions with a high probability of occurrence of singularity (Fig. 2). Table 2 shows the average element numbers for each of the parts used in finite element models.

All models were fixed rigidly to prevent displacement in

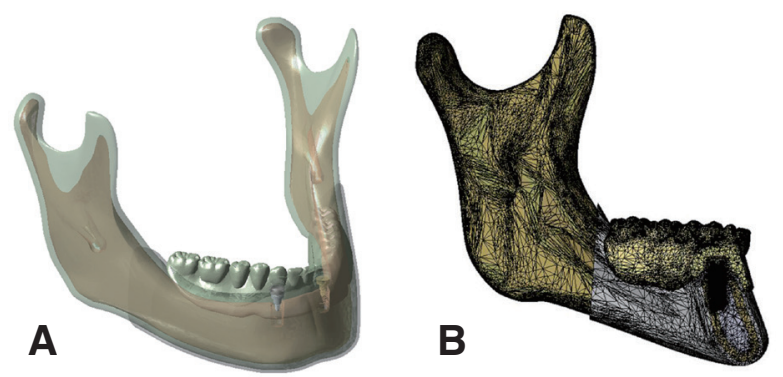

Fig. 2. The mandible model used in the present study. (A) Ready-to-analyze model including implants, implant superstructures and prosthesis. (B) Cross-section view of the meshed model.

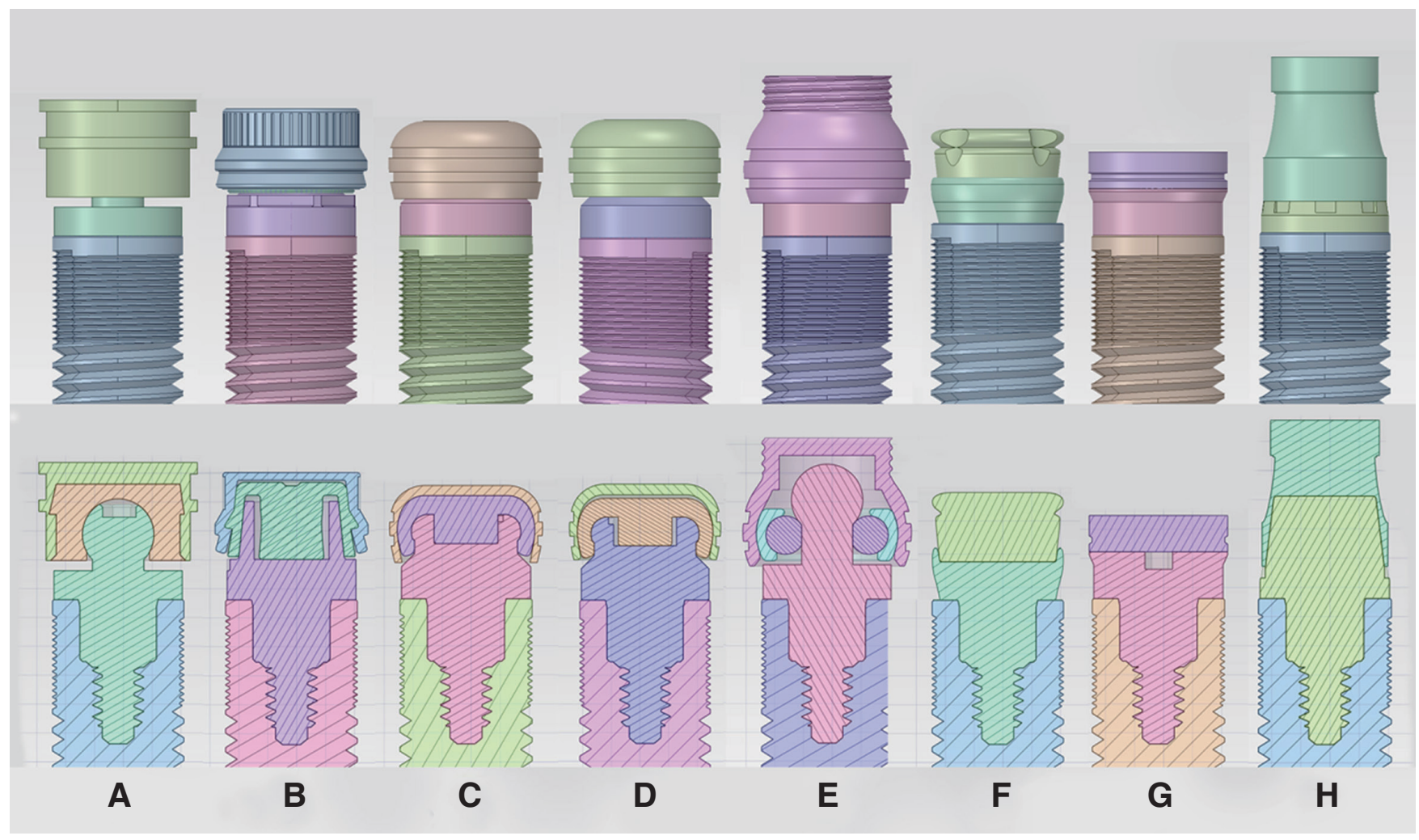

Fig. 1. Attachment models and cross-sectional images modeled in the present study. (A) Ball attachment, (B) ERA attachment, (C) Locator attachment, (D) Zest attachment, (E) O-Ring attachment, (F) Dentium Magnet, (G) Dyna Magnet, (H) Titanmagnetics. 
Table 1. The material properties of each part of the FEA models

\begin{tabular}{|c|c|c|c|c|}
\hline Component & Material & Elastic modulus (GPa) & Poisson ratio & References \\
\hline Cortical bone & - & 13.70 & 0.30 & 17,18 \\
\hline Trabecular bone & - & 1.37 & 0.30 & 13 \\
\hline Gingiva & - & 0.0028 & 0.40 & 15 \\
\hline Base and teeth & Acrylic & 8.30 & 0.28 & 17 \\
\hline Implant & Titanium & 115.00 & 0.35 & 18 \\
\hline Abutment (matrix) and metallic cap attachment & Titanium grade 4 & 114.00 & 0.30 & 14 \\
\hline Insert plastic patrix attachment & Nylon rubber & 0.005 & 0.45 & 16 \\
\hline
\end{tabular}

Table 2. Average number of elements and nodes of model parts

\begin{tabular}{lrr}
\hline \multicolumn{1}{c}{ Model part } & Elements & Nodes \\
\hline Cortical bone & 775.229 & 1.014 .072 \\
Trabecular bone & 260.036 & 311.844 \\
Gingiva & 112.008 & 137.061 \\
Base and teeth & 252.130 & 341.157 \\
Implants & 2.654 .968 & 3.013 .814 \\
Abutment & 1.047 .282 & 1.220 .490 \\
Metallic cap & 8.893 & 15.926 \\
Insert plastic patrics & 4.265 & 7.467 \\
\hline
\end{tabular}

$\mathrm{x}, \mathrm{y}$, and $\mathrm{z}$ axes. The fixation was carried out from the attachment areas of lateral pterygoid, temporalis, medial pterygoid, and masseter muscles to the mandible and from where the condyle head touches the discus articularis. ${ }^{11}$

In the present study, the centric relationship, protrusive movement, and lateral movement loads were simulated in bilateral balanced occlusion. A previous study was taken as a reference for the application. ${ }^{22}$ In this context, the forces were applied from the tubercle contact points perpendicularly to the surface it was defined. ${ }^{22}$ In addition, the load formed during unilateral chewing of food mass had been applied in accordance with previous studies. ${ }^{6,14}$ Load values and manner of the application were as follows:

Full mouth bite load: A total of $450 \mathrm{~N}$ was applied vertically to the related surfaces and from the tubercle contact points formed at maximum intercuspation in the bilateral balanced occlusion. ${ }^{22}$

Protrusive movement load: A total of $400 \mathrm{~N}$ was applied vertically to the related surfaces and from the tubercle contact points formed in the protrusive movement in the bilateral balanced occlusion. ${ }^{22}$

Lateral movement load: A total of $400 \mathrm{~N}$ was applied vertically to the related surfaces and from the tubercle contact points formed in the lateral movement in the bilateral balanced occlusion. The left side was the rotating side. ${ }^{22}$

Unilateral bite load: A load of $200 \mathrm{~N}$ was applied verti- cally from the central fossa of the left 1 st molar tooth using the half-round object (This object was designed in three dimensions and touches not a single point of the 1st molar tooth, but all the tubercle slopes. It represents a hard piece of food). ${ }^{11,18}$

Analyses were performed according to these boundary conditions. The results were obtained by analyzing thirtytwo different models with the presence of eight different attachment types and four different load conditions. Stress outputs were obtained as the maximum principal stress $\left(\sigma_{\max }\right)$ from the cortical bone tissue and the maximum Equivalent von-Mises stress from dental implants and abutments. In the models where the forces are symmetrically applied and therefore the stress distribution is symmetrically distributed, findings were obtained from one side. In models showing asymmetric stress distribution, maximum stresses were obtained on both sides separately. The lower and upper limits in the color bar were standardized in order to make comparisons between the models in obtaining the images containing the findings. The findings were recorded as tables showing the stress values and figures showing the stress distributions. The figures showing the stress distribution were created by providing color distribution standardization among the models.

\section{RESULTS}

Full mouth bite load: In the first load, representing the full mouth bite, higher stresses were observed in the abutment, dental implant, and bone in the magnet attachments. The highest stresses were observed in the model with a Titanmagnetics attachment (For abutment, dental implant, and bone, 9.9, 17.7, and 19.4 $\mathrm{MPa}$, respectively). Among the non-magnet attachment systems, stresses were higher in the models with ERA and Locator attachments compared to others (For abutment, dental implant, and bone: 1.9, 12.7, and 5.27 $\mathrm{MPa}$ for ERA, 1.84, 11.3, and 3.5 MPa for Locator attachments, respectively; Fig. 3).

Protrusive movement load: The highest stress values in the protrusive movement occurred in the model with a Titanmagnetics attachment (for abutment, dental implant, and bone: 9.9, 16.8, and $13.1 \mathrm{MPa}$, respectively). This was 
followed by the models with ERA and Locator attachments, respectively (for ERA attachment: $10,12.5$, and $11.3 \mathrm{MPa}$, for Locator attachment: $8.1,10.8$, and $8.1 \mathrm{MPa}$, respective- ly). The lowest stress value was observed in the models with Zest and O-Ring attachments (Fig. 4 and Fig. 5).

Lateral movement load: as with previous loads, the high-

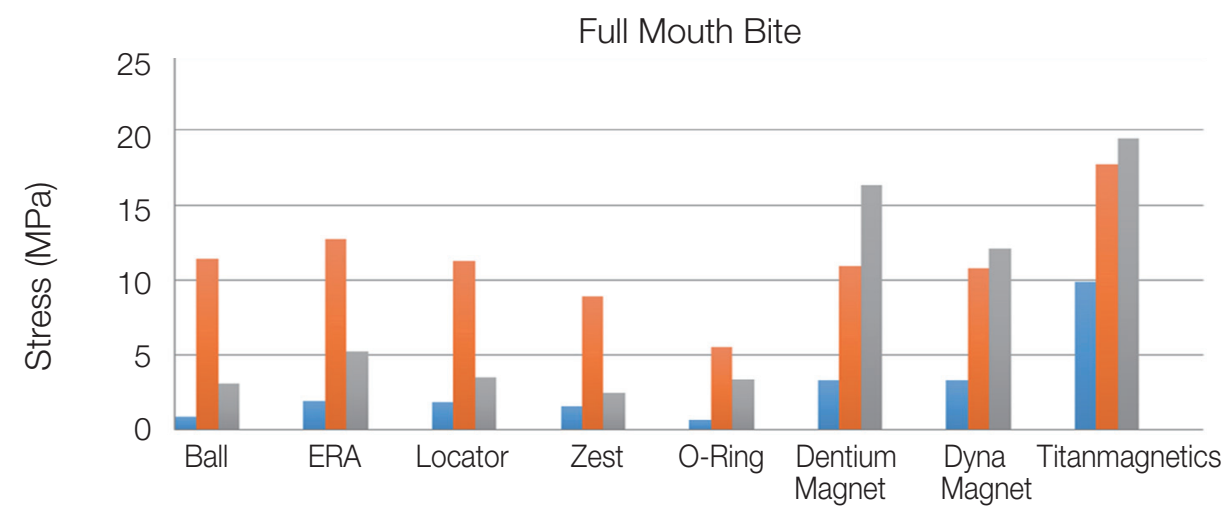

\begin{tabular}{|c|c|c|c|c|c|c|c|c|}
\hline abutment & 0.9 & 1.9 & 1.84 & 1.56 & 0.7 & 3.29 & 3.28 & 9.9 \\
\hline - Implant & 11.4 & 12.7 & 11.3 & 8.9 & 5.5 & 10.9 & 10.8 & 17.7 \\
\hline Bone & 3.1 & 5.24 & 3.5 & 2.5 & 3.4 & 16.3 & 12.1 & 19.4 \\
\hline
\end{tabular}

\section{Protrusive Movement}

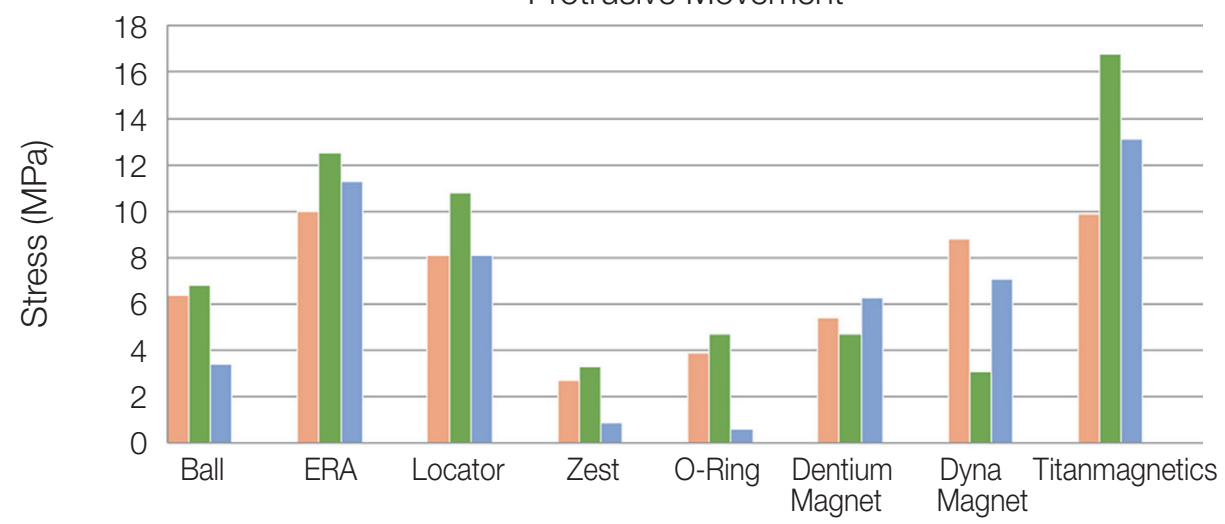

\begin{tabular}{|c|c|c|c|c|c|c|c|c|}
\hline Abutment & 6.4 & 10 & 8.1 & 2.7 & 3.9 & 5.4 & 8.8 & 9.9 \\
\hline E Implant & 6.8 & 12.5 & 10.8 & 3.3 & 4.7 & 4.7 & 3.1 & 16.8 \\
\hline Bone & 3.4 & 11.3 & 8.1 & 0.9 & 0.6 & 6.3 & 7.1 & 13.1 \\
\hline
\end{tabular}

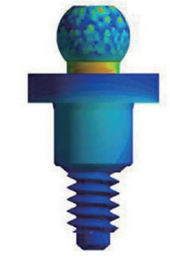

A

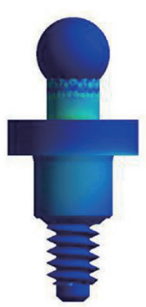

E

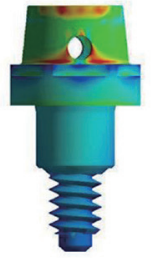

B

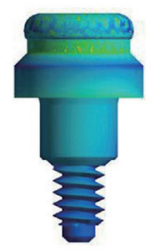

C

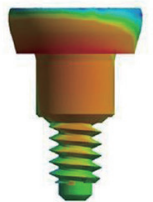

$\mathbf{F}$

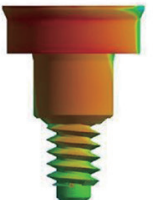

G

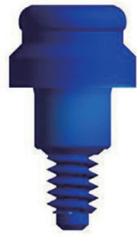

D

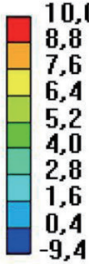

Fig. 4. Stress comparison in bone, implants and attachments on protrusive movement (MPa).
Fig. 3. Stress comparison in bone, implants and attachments on full mouth bite (MPa).
Fig. 5. Stress patterns on abutments in the protrusive movement. (A) Ball attachment, (B) ERA attachment, (C) Locator attachment, (D) Zest attachment, (E) O-Ring attachment, (F) Dentium Magnet, (G) Dyna Magnet, (H) Titanmagnetics. Stress values are in MPa. 
est stress values were observed in Titanmagnetics attachments (for abutment, dental implant, and bone, 7.2, 17.5, and 33.1, respectively). Fewer stresses occurred on the nonrotating side on all attachment types in the lateral movement (Fig. 6 and Fig. 7). In ERA and Locator attachments, on the bone tissue, stresses were more than doubled on the nonrotating side than the rotating side (for ERA and Locator attachments, non-rotating side stresses on the bone were 30.4 $\mathrm{MPa}$ and 28.2 $\mathrm{MPa}$, respectively). Considering the other load conditions, higher stresses were observed in the bone tissue compared to the abutments and dental implants in this load condition. High stress changes were significant when comparing the stresses transmitted to the bone between the attachment types and between the rotating and non-rotating sides (Fig. 6 and Fig. 7).

Unilateral bite load: the highest stress values were observed in the model with the Titanmagnetics attachment (on the attachment, dental implant, and bone; 15.4, 13.5, and 16.1 MPa, respectively). Similarly to the other load conditions, magnet attachments were followed by ERA and Locator attachments in terms of high-stress levels. The most favorable stress distribution was observed in Zest attachment (for abutment, dental implant, and bone; 2.2, 5.1, and 2.1 $\mathrm{MPa}$ on rotating side, $0.5,3.1$, and $0.8 \mathrm{MPa}$ on the non-rotating side). In contrast to the lateral movement load, higher stress values were observed on the rotating side of all attachment types (Fig. 8 and Fig. 9).

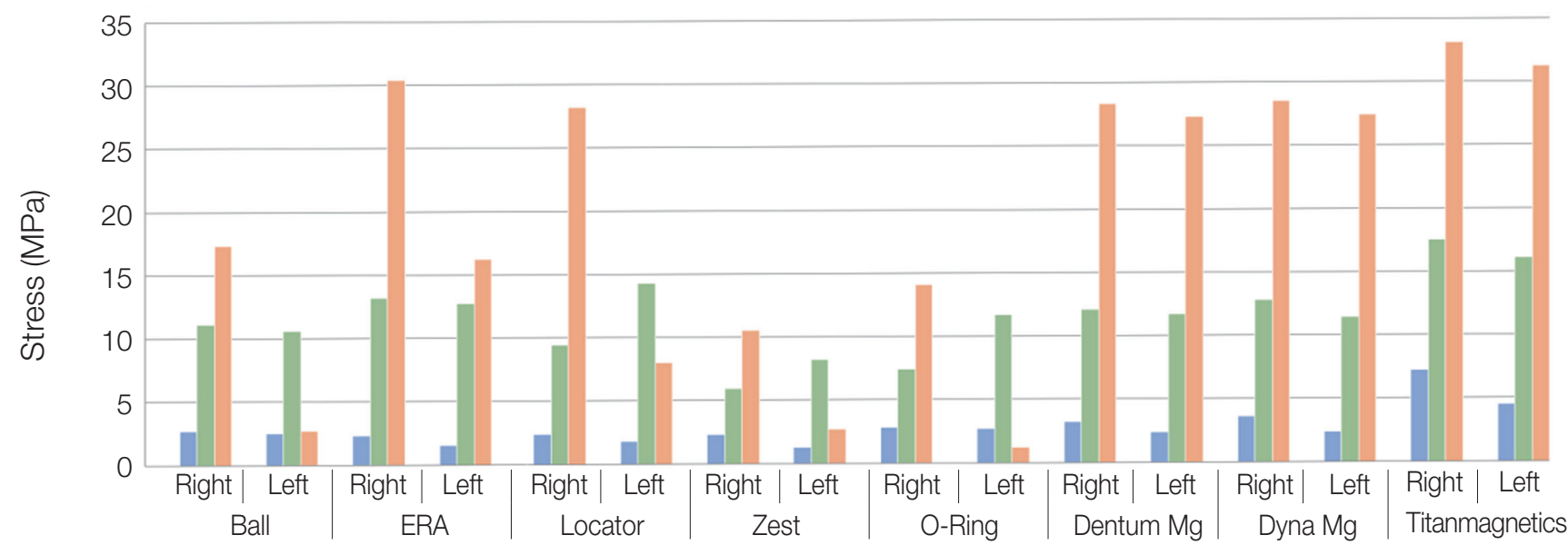

Attachment Type

\begin{tabular}{|c|c|c|c|c|c|c|c|c|c|c|c|c|c|c|c|c|}
\hline abutment & 2.7 & 2.5 & 2.3 & 1.5 & 2.4 & 1.8 & 2.3 & 1.3 & 2.8 & 2.7 & 3.2 & 2.4 & 3.6 & 2.4 & 7.2 & 4.5 \\
\hline Implant & 11.1 & 10.6 & 13.2 & 12.7 & 9.4 & 14.3 & 5.9 & 8.2 & 7.4 & 11.7 & 12.1 & 11.7 & 12.8 & 11.4 & 17.5 & 16.1 \\
\hline Bone & 17.3 & 2.7 & 30.4 & 16.2 & 28.2 & 8 & 10.5 & 2.7 & 14.1 & 1.2 & 28.3 & 27.3 & 28.5 & 27.4 & 33.1 & 31.2 \\
\hline
\end{tabular}

Fig. 6. Stress comparison in bone, implants and attachments on lateral movement (MPa).

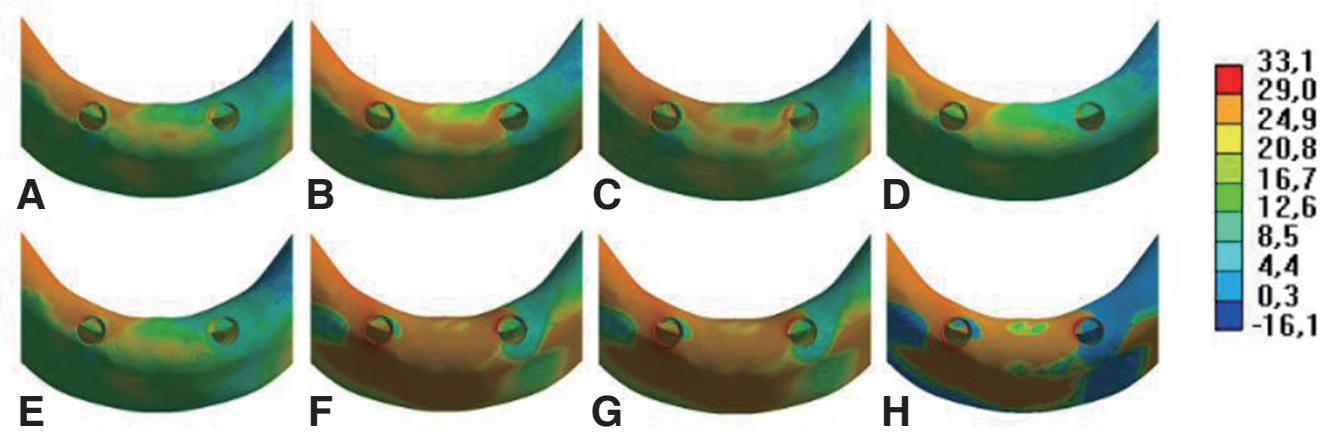

Fig. 7. Stress patterns on cortical bone in the lateral movement. (A) Ball attachment model, (B) ERA attachment model, (C) Locator attachment model, (D) Zest attachment model, (E) O-Ring attachment model, (F) Dentium Magnet model, (G) Dyna Magnet model, $(\mathrm{H})$ Titanmagnetics model. Stress values are in MPa. 


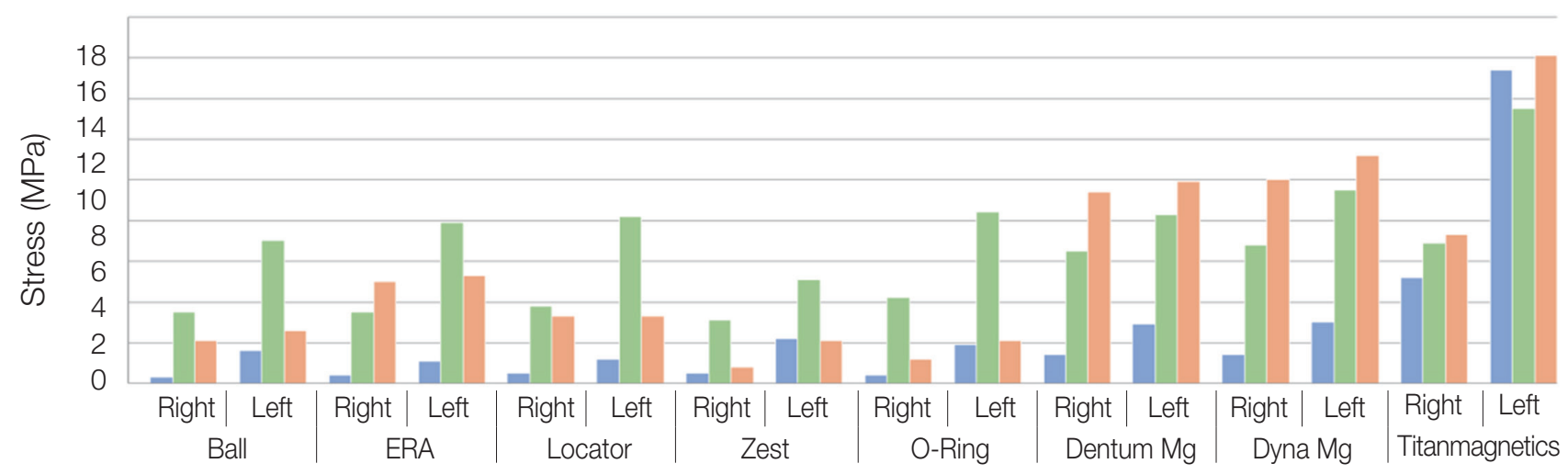

Attachment Type

\begin{tabular}{|c|c|c|c|c|c|c|c|c|c|c|c|c|c|c|c|c|}
\hline Abutment & 0.3 & 1.6 & 0.4 & 1.1 & 0.5 & 1.2 & 0.5 & 2.2 & 0.4 & 1.9 & 1.4 & 2.9 & 1.4 & 3 & 5.2 & 15.4 \\
\hline Implant & 3.5 & 7 & 3.5 & 7.9 & 3.8 & 8.2 & 3.1 & 5.1 & 4.2 & 8.4 & 6.5 & 8.3 & 6.8 & 9.5 & 6.9 & 13.5 \\
\hline Bone & 2.1 & 2.6 & 5 & 5.3 & 3.3 & 3.3 & 0.8 & 2.1 & 1.2 & 2.1 & 9.4 & 9.9 & 10 & 11.2 & 7.3 & 16.1 \\
\hline
\end{tabular}

Fig. 8. Stress comparison in bone, implants and attachments on unilateral bite (MPa).

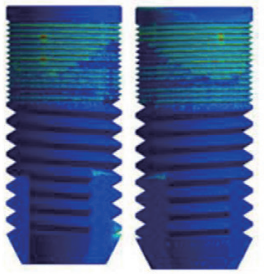

A

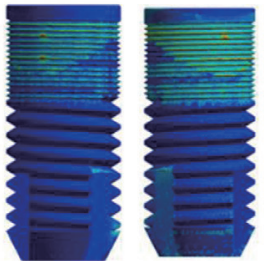

E

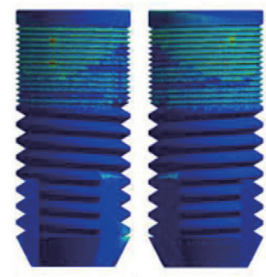

B

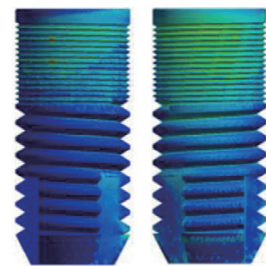

$\mathbf{F}$

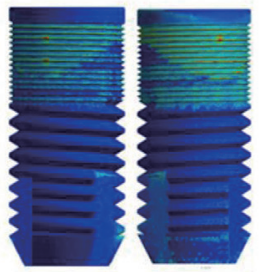

C

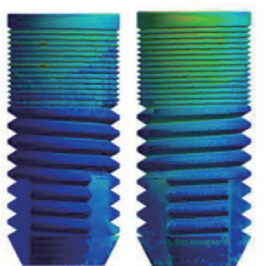

G

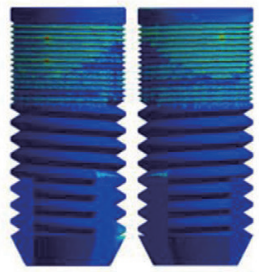

D

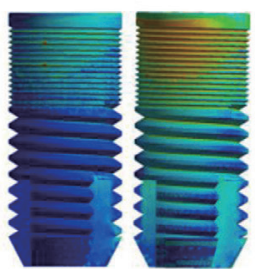

H

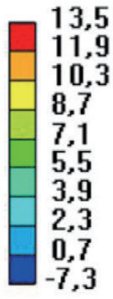

Fig. 9. Stress patterns on implants in the unilateral bite. (A) Ball attachment implants, (B) ERA attachment implants, (C) Locator attachment implants, (D) Zest attachment implants, (E) O-Ring attachment implants, (F) Dentium Magnet implants, (G) Dyna Magnet implants, (H) Titanmagnetics implants. Stress values are in MPa.

\section{DISCUSSION}

According to the result of the present study, attachment types working with different principles caused different amounts of stress on bone tissue and dental implant parts. The null hypothesis was rejected.

FEA has frequently been preferred in the medical field in recent years since it can be applied to complex structures containing irregular geometry and the structure to be examined can be highly imitated by standardizing various characteristics in the comparison of different situations. ${ }^{23}$ In the FEA method, dental implant, superstructures, localizations and the amounts of the stresses occurring in the bone can be easily examined. Due to these advantages, the FEA method was preferred in the present study. In the FEA method, obtaining realistic results is in parallel with the correct imitation of the models. ${ }^{23}$ In the similar studies previously conducted, the process of load application was mostly performed without simulating the entire prosthesis structure, directly on the attachment, or by applying a force from a single point in the cases where the entire prosthetic structure was designed. ${ }^{6,24}$ In the present study, the mandible, dental implants, attachment types, and prosthesis were designed in detail and forces were applied in a way to represent the different conditions of the bilateral balanced occlusion, a recommended type of occlusion in full prostheses. 
In all the load conditions, the forces were applied from the tubercle contact points in accordance with the slope of the relevant surface. Therefore, in the present study, the intraoral function was simulated in a more realistic way compared to the previous studies.

It has been reported in the literature that magnet attachments increase prosthesis retention and provide a high level of patient satisfaction. ${ }^{15,25}$ However, the effects of magnet attachments on stress transmission have not been investigated sufficiently. In the present study, it was observed that in all the load conditions, the stresses occurring in the attachment structure, dental implant, and bones were higher in the models with magnet attachments. In a study performed by Takahashi et al., ball, Locator, and magnet attachments were used and the stresses in the dental implants were measured by Strain Gauge method. ' The results of the study showed that lower stresses occurred in magnet type attachments. It has been reported that FEA method and Strain Gauge method present different but complementary findings. ${ }^{26,27}$ However, the methodology of the study performed by Takashi et al. is insufficient in terms of the magnitude and distribution of the loads applied. ' In the present study, data were obtained from the abutment, dental implant, and bone tissue, while Takashi et al. provided data only from dental implants. Amer et al. ${ }^{28}$ compared ball and magnet attachments in dental implant-retained obturators and reported higher stresses in magnet attachments in a way to support findings of the present study.

Another factor in the formation of higher stresses in magnet attachments may be the properties of the parts it contains. While there are plastic connecting parts in all other attachment types examined in the present study, there is no such structure in magnet attachments. The force-breaking properties of plastic parts may play an effective role in the formation of lower stresses.

Findings from a review study by Kim et al. ${ }^{29}$ showed that more dental implant loss was observed in treatments with magnet-type attachments. However, in the study, magnet attachments were not classified by type. Among all the attachments in the present study, the highest stress was observed in the models with Titanmagnetics attachments in all the cases. When the structure of the Titanmagnetics attachment is examined, it is seen that the magnet with two opposite poles is intertwined and the walls of the female part are so high that they do not allow rotation. This is probably the cause of high stress. Since in this case the load from the prosthesis may be transferred less to the tissue and more to the attachment parts.

Overdentures retained by two dental implants are more unstable than prostheses with more dental implants and retainers are exposed to multiple directional stresses, therefore, this situation should be considered in the design of the attachment type to reduce stresses to the bone and dental implant. It has been stated previously that the attachment types having spherical parts are more advantageous in this regard. ${ }^{30-32}$ In the present study, observed lower stresses in ball attachment and O-Ring attachment containing spherical type parts support this finding. El-Anwar et al. ${ }^{33}$ stated that Locator attachments cause less stress than ball attachments. Unsal et al. ${ }^{10}$ reported that better biomechanical results were obtained in models with ball attachments. However, in both studies, the loading conditions were not suitable and the applied forces were far from imitation of the oral environment. In this study, no significant difference was observed in the stresses occurring in abutment, dental implant, and bone tissue in Locator and ball attachment types.

The lowest stress values were observed in the models with Zest and O-Ring type attachments. The stress values of these two types of attachments were similarly low when the attachment structure, dental implant, and bone tissue were examined in all the load conditions. In terms of the design, there is a similarity between the Zest attachment and the Locator attachment. In the Zest attachment, rotation is possible in various positions that the prosthesis will take with the space provided between the housing and the plastic rubber. Zest attachment with this feature has been reported to provide better clinical results than Ball attachment. ${ }^{34}$ O-Ring attachment is more similar to the Ball attachment system. However, it has a circular plastic rubber in its structure and thus allows more active movement; loads are transferred less to the attachment and more to the tissue.

In the present study, in lateral movement and unilateral bite, the amounts of stress on the abutment, dental implant, and bone tissue were very different from each other on the right and left sides. This is clearly observed in the visuals of the stress distributions occurring in bone tissue in lateral movement. This observation suggests that single point application of the load may not provide accurate data when comparing attachment types. ${ }^{16,24}$ At different angles of load, the behavior of an attachment in stress transmission may be different. ${ }^{10,35}$ Therefore, in the comparison of different attachment types, occlusal forces should be applied in a way to realistically simulate chewing.

The chewing loads on the two-implant overdenture prostheses are transmitted to the bone tissue through the dental implants and the soft tissues where the prosthetic base sits. Although much higher loads are applied, the reason for the formation of lower stresses on the parts examined, in general, is that most of these loads are transferred to the supporting tissues through the base of the prosthesis. The stress-bearing limit of cortical bone and titanium dental implants has been reported as $170-190 \mathrm{MPa}^{36}$ and 1119 $\mathrm{MPa},{ }^{37}$ respectively. When the stresses transmitted to the dental implant and bone were evaluated, it was seen that these values were much lower than the resistance limit of the dental implant or bone. The current knowledge in the literature also supports this. ${ }^{10,38}$ It has been reported in the literature that the rate of the situations such as dental implant neck fractures, attachment screw fractures, or excessive bone resorption is low in the two dental implantretained overdenture prostheses. ${ }^{39}$ The stresses transmitted to the attachment structure were evaluated by various authors in terms of the quicker deformation of the attachments. ${ }^{14,40}$ Less stress transmission to tissues may be impor- 
tant for patient satisfaction and chewing effectiveness. For this reason, although there are many types of attachments, new attachment systems continue to be developed. ${ }^{29}$ The attachment parts of the systems examined in the present study can be easily replaced and renewed in the case that they are worn. In the selection of the attachment, the condition of the case can be taken into consideration by focusing on the issue that the support should be taken from the dental implant or the bone around it or the crest structure supporting the prosthesis.

The FEA method allows the standardization of many factors to change only those conditions that are to be investigated. ${ }^{23}$ However, as a limitation in the present study, in the FEA method, realistic simulation of some factors such as bone tissue, dental implant-bone connection, saliva, temperature changes, and natural material aging is not possible. Further clinical studies are needed to investigate the effects of attachment types on stress transmission. If the findings of the FEA studies are interpreted considering the findings of the clinical studies, more accurate results can be obtained. In the present study, various types of attachments in two dental implant-supported overdenture prostheses were compared in terms of stress transmission. In these types of prostheses, one of the important complaints of the patients is an insufficient attachment. ${ }^{41}$ An important alternative to these attachment systems is an attachment system containing bars. Findings obtained in a current systematic review study show that there is no significant difference between bar, ball, and O-Ring attachment types in terms of retention, mastication, maximum occlusal force, and bone loss. ${ }^{42}$ In the future, with the attachment types evaluated in this study, long-term clinical studies that include bar attachment systems should be conducted.

In the literature, the production techniques of single dental implant-retained mandibular overdenture have also been reported. These treatments are generally preferred in cases where the cost of two dental implant treatments cannot be covered by patients. Studies show that single dental implantretained mandibular overdentures may be among the alternative treatment options, especially when there is complete denture in the opposite arch. ${ }^{43}$ In the future, studies on comparing single and two dental implant-overdenture prostheses in terms of stress transmission, as well as investigating which attachment type is better in single dental implantretained mandibular overdenture will provide an important contribution to the literature.

\section{CONCLUSION}

According to the results of the present study, the following conclusions can be drawn. Attachment types permitting rotation and tolerating various angles created lower stresses on the bone, dental implants, and abutments. Zest and O-Ring type attachments, which allow more rotation, created lower stresses on attachment parts, dental implants, and bone.

\section{ORCID}

Nurullah Turker https://orcid.org/0000-0003-4020-684X

Ulviye Sebnem Buyukkaplan https://orcid.org/0000-0002-49622930

\section{REFERENCES}

1. Zhang L, Lyu C, Shang Z, Niu A, Liang X. Quality of life of implant-supported overdenture and conventional complete denture in restoring the edentulous mandible: A systematic review. Implant Dent 2017;26:945-50.

2. Thomason JM, Kelly SA, Bendkowski A, Ellis JS. Two implant retained overdentures-a review of the literature supporting the McGill and York consensus statements. J Dent 2012;40:22-34.

3. Karayazgan-Saracoglu B, Atay A, Korkmaz C, Gunay Y. Quality of life assessment of implant-retained overdentures and fixed metal-acrylic resin prostheses in patients with marginal mandibulectomy. J Prosthet Dent 2017;118:551-60.

4. Schimmel M, Müller F, Suter V, Buser D. Implants for elderly patients. Periodontol 2000 2017;73:228-40.

5. Ying Z, Gonda T, Maeda Y. Influence of attachment height and shape on lateral force transmission in implant overdenture treatment. Int J Prosthodont 2017;30:586-91.

6. Porter JA Jr, Petropoulos VC, Brunski JB. Comparison of load distribution for implant overdenture attachments. Int J Oral Maxillofac Implants 2002;17:651-62.

7. Manju V, Sreelal T. Mandibular implant-supported overdenture: an in vitro comparison of ball, bar, and magnetic attachments. J Oral Implantol 2013;39:302-7.

8. Leão RS, Moraes SLD, Vasconcelos BCE, Lemos CAA, Pellizzer EP. Splinted and unsplinted overdenture attachment systems: A systematic review and meta-analysis. J Oral Rehabil 2018;45:647-56.

9. Takahashi T, Gonda T, Tomita A, Maeda Y. Effect of attachment type on implant strain in maxillary implant overdentures: Comparison of ball, locator, and magnet attachments. Part 2: Palateless dentures. Int J Oral Maxillofac Implants 2018;33:357-64.

10. Unsal GS, Erbasar GNH, Aykent F, Ozyilmaz OY, Ozdogan MS. Evaluation of stress distribution on mandibular implantsupported overdentures with different bone heights and attachment types: A 3D finite element analysis. J Oral Implantol 2019;45:363-70.

11. Daas M, Dubois G, Bonnet AS, Lipinski P, Rignon-Bret C. A complete finite element model of a mandibular implant-retained overdenture with two implants: comparison between rigid and resilient attachment configurations. Med Eng Phys 2008;30:218-25.

12. Baker, EW, Schünke, M, Schulte, E, Schumacher, U. Anatomy for dental medicine. 2nd ed. New York; Thieme; 2015. p. 403.

13. Larheim TA, Svanaes DB. Reproducibility of rotational panoramic radiography: mandibular linear dimensions and angles. Am J Orthod Dentofacial Orthop 1986;90:45-51.

14. Brunski JB, Puleo DA, Nanci A. Biomaterials and biomechan- 
ics of oral and maxillofacial implants: current status and future developments. Int J Oral Maxillofac Implants 2000;15:15-46.

15. Cheng T, Sun G, Huo J, He X, Wang Y, Ren YF. Patient satisfaction and masticatory efficiency of single implant-retained mandibular overdentures using the stud and magnetic attachments. J Dent 2012;40:1018-23.

16. Chun HJ, Park DN, Han CH, Heo SJ, Heo MS, Koak JY. Stress distributions in maxillary bone surrounding overdenture implants with different overdenture attachments. J Oral Rehabil 2005;32:193-205.

17. Mitrani R, Brudvik JS, Phillips KM. Posterior implants for distal extension removable prostheses: a retrospective study. Int J Periodontics Restorative Dent 2003;23:353-9.

18. Silva GC, Mendonça JA, Lopes LR, Landre J Jr. Stress patterns on implants in prostheses supported by four or six implants: a three-dimensional finite element analysis. Int J Oral Maxillofac Implants 2010;25:239-46.

19. Rand A, Stiesch M, Eisenburger M, Greuling A. The effect of direct and indirect force transmission on peri-implant bone stress - a contact finite element analysis. Comput Methods Biomech Biomed Engin 2017;20:1132-9.

20. Tillitson EW, Craig RG, Peyton FA. Friction and wear of restorative dental materials. J Dent Res 1971;50:149-54.

21. Liu J, Pan S, Dong J, Mo Z, Fan Y, Feng H. Influence of implant number on the biomechanical behaviour of mandibular implant-retained/supported overdentures: a three-dimensional finite element analysis. J Dent 2013;41:241-9.

22. Türker N, Büyükkaplan US, Sadowsky SJ, Özarslan MM. Finite element stress analysis of applied forces to implants and supporting tissues using the "All-on-Four" concept with different occlusal schemes. J Prosthodont 2019;28:185-94.

23. Trivedi S. Finite element analysis: A boon to dentistry. J Oral Biol Craniofac Res 2014;4:200-3.

24. Dashti MH, Atashrazm P, Emadi MI, Mishaeel S, Banava S. The effects of two attachment types on the stresses introduced to the mandibular residual ridge: a 3D finite element analysis. Quintessence Int 2013;44:585-90.

25. Ellis JS, Burawi G, Walls A, Thomason JM. Patient satisfaction with two designs of implant supported removable overdentures; ball attachment and magnets. Clin Oral Implants Res 2009;20:1293-8.

26. Eser A, Akça K, Eckert S, Cehreli MC. Nonlinear finite element analysis versus ex vivo strain gauge measurements on immediately loaded implants. Int J Oral Maxillofac Implants 2009;24:439-46.

27. Iplikçioğlu H, Akça K, Cehreli MC, Sahin S. Comparison of non-linear finite element stress analysis with in vitro strain gauge measurements on a Morse taper implant. Int J Oral Maxillofac Implants 2003;18:258-65.

28. Amer MM, Rashad HA, Abdallah S. Stress distribution of implant retained obturators using different types of attachments: A three dimensional finite element analysis. Tanta Dent J 2015;12:30-40.

29. Kim HY, Lee JY, Shin SW, Bryant SR. Attachment systems for mandibular implant overdentures: a systematic review. J Adv Prosthodont 2012;4:197-203.
30. Menicucci G, Ceruti P, Barabino E, Screti A, Bignardi C, Preti G. A preliminary in vivo trial of load transfer in mandibular implant-retained overdentures anchored in 2 different ways: allowing and counteracting free rotation. Int $\mathrm{J}$ Prosthodont 2006;19:574-6.

31. Oetterli M, Kiener P, Mericske-Stern R. A longitudinal study on mandibular implants supporting an overdenture: The influence of retention mechanism and anatomic-prosthetic variables on peri-implant parameters. Int J Prosthodont 200; 14:536-42.

32. Wiemeyer AS, Agar JR, Kazemi RB. Orientation of retentive matrices on spherical attachments independent of implant parallelism. J Prosthet Dent 2001;86:434-7.

33. El-Anwar MI, El-Taftazany EA, Hamed HA, ElHay MAA. Influence of number of implants and attachment type on stress distribution in mandibular implant-retained overdentures: Finite element analysis. Open Access Maced J Med Sci 2017;5:244-9.

34. Cakarer S, Can T, Yaltirik M, Keskin C. Complications associated with the ball, bar and Locator attachments for implantsupported overdentures. Med Oral Patol Oral Cir Bucal 2011; 16:e953-9.

35. Vafaei F, Khoshhal M, Bayat-Movahed S, Ahangary AH, Firooz F, Izady A, Rakhshan V. Comparative stress distribution of implant-retained mandibular ball-supported and barsupported overlay dentures: a finite element analysis. J Oral Implantol 2011;37:421-9.

36. Natali AN. Dental biomechanics. 1st ed. New York, CRC Press; 2003. p. 74-8.

37. Sakaguchi RL. Craig's restorative dental materials. 12nd ed. Houston, Elsevier Health Sciences; 2006. p. 93-101.

38. Ozan O, Ramoglu S. Effect of implant height differences on different attachment types and peri-implant bone in mandibular two-implant overdentures: 3D finite element study. J Oral Implantol 2015;41:e50-9.

39. Goodacre CJ, Bernal G, Rungcharassaeng K, Kan JY. Clinical complications with implants and implant prostheses. J Prosthet Dent 2003;90:121-32.

40. Binon PP. Implants and components: entering the new millennium. Int J Oral Maxillofac Implants 2000;15:76-94.

41. Scherer MD, McGlumphy EA, Seghi RR, Campagni WV. Comparison of retention and stability of implant-retained overdentures based upon implant number and distribution. Int J Oral Maxillofac Implants 2013;28:1619-28.

42. Gonçalves F, Campestrini VLL, Rigo-Rodrigues MA, Zanardi PR. Effect of the attachment system on the biomechanical and clinical performance of overdentures: A systematic review. J Prosthet Dent 2020;123:589-94.

43. de Souza Batista VE, Vechiato-Filho AJ, Santiago JF Jr, Sonego MV, Verri FR, Dos Santos DM, Goiato MC, Pellizzer EP. Clinical viability of single implant-retained mandibular overdentures: a systematic review and meta-analysis. Int J Oral Maxillofac Surg 2018;47:1166-77. 